\title{
EDUCATIONAL
} TECHNOLOGY

\section{Educational radio in its third decade: Redefining the concept of educational broadcasting in terms of new expectations and financial restraint}

\author{
W. K. McGinnis \\ Station Manager of 6UVS-FM
}

In seven years of involvement with institutionally-based educational public broadcasting in Western Australia I have observed a process of evolution within the sector, in terms of its raison d'etre as well as fundamental reorientations in the mechanisms of financial support. A prior four years of experience in similar operations in North America have contributed to my perceptions of where the future opportunities for educational broadcasting lie and the factors which have placed us on the current path. In August 1986, the Public Broadcasting Association of Australia convened a weekend conference entitled "The Practice of Educational Radio". At this gathering I was surprised to find that my conclusions were not isolated, since many of my colleagues expressed parallel views.

Those who are survivors of the earliest days of Australian educational radio or those who have spent a good deal of time reading documentation from the archives will attest to a significant discrepancy between what educational broadcasting was expected to be and what it is today. Some of this departure can be explained by a duality of purpose which was inherent in each radio station from the beginning: that of being formed as an educational radio station but licensed as a public broadcasting operation. The two aspects are somewhat mutually exclusive and the experience of the last decade can be seen as a succession of attempts to reconcile this dilemma.

Much of the initial academic support for the inauguration of independent educational broadcasting in Australia seems to be based on the anticipation of the new services taking the form of transmissions of 
specific lectures and tutorials, many being used for official course credit. This expectation was based on the example of the British Open University system which utilised mainly low power and wired systems to serve a geographical area often not much larger than the institutions' campuses. In the early days some educators apparently held the rather utopian assumptions that listeners would desert the $\mathrm{ABC}$ and commercial broadcasting en masse once the airwaves were used to give the public access to the benefits of teaching in progress.

In legal terms the "blueprint" for Australian public broadcasting was the American example. In the US there are a few educational public radio stations providing specific course-related transmissions. However, the overwhelming majority adhere to "soft core" educational approaches, general promotional activities for associated academic institutions and provision of programs not directly related to education but culturally alternative to options offered by commercial radio stations. The educational broadcaster is seen as a true form of mass media and is required to demonstrate contributions to society reaching beyond the walls of academia in order to justify itself to the relicensing authorities.

In the first wave of Australian public radio licences issued, those with educational briefs were the majority. Once underway the services found themselves caught in the crossfire between educators who wanted radio to educate in the literal sense and a listenership who demanded alternative music and community information. The nature of the public broadcasting licence itself stressed service to the community as the primary objective. Most of these early educational radio stations served much larger geographical areas than British Open University transmissions. Once initiated, daily broadcasting took on a momentum of its own which sharpened the paradoxical nature of the situation. As programs aimed at the community began to gather audiences of significant size (well beyond the administrative capabilities of external studies and extension departments to handle) it became clear that the options were to "narrowcast" to small groups of the academically committed, to make an attempt at emassing larger audiences through more accessible approaches or to try to attain a precarious balance between the two. Public broadcasters, many now having attained employment status as professional broadcasters, began to question whether extending course work to the air waves defined them as real broadcasters or high-tech lecture theatre technicians. Were they producing radio programs or forcing educative projects down the throats of an uncooperative radio public?

This inherent contradiction was escalated further by the financial concerns of the "Lean 80s". The educational stations and the tertiary institutions associated with them both sustained budget cuts and faced a scenario of "no growth" at best. The drought chronologically corresponded to a period 
when replacement of the worn out "first generation" equipment was critical. Stations were forced to seek additional funding through external sources including personal subscriptions, more community access users and corporate sponsorship. On the whole, educational public broadcasters have been quite principled in embarking in these new funding directions while still maintaining their integrity and editorial independence as public broadcasters, though pure educative objectives were often sacrificed in the process. A prerequisite of all of these recipes for outside funding was wider audience appeal than a specialised lecture format is capable of generating.

Many of the tertiary institutions themselves now seem to be coming to similar conclusions about the orientation of their public radio stations. Outside funding is beginning to be viewed as an admirable objective since this means less institutional financial resources need to be diverted to the support of campus stations. Many academic institutions are starting to accept the realisation that effective community relations are essential if universities, institutes and colleges are to continue to receive reasonable government funding with the full support of the wider community. A radio station attached to an institution with demonstrable public relations clout will promote campus activities with far more cost efficiency than would the purchase of expensive external advertising. There may be possibilities for using the radio service as an important pillar in the strategy to attract additional endowment funds to the tertiary institution from private benefactors, corporate interests and alumni. At any rate these public relations strategies all demand the same type of relative accessibility in programming also essential for successful radio station fundraising.

It would be wrong to assume that the point of this narrative is to illustrate a failure of educational broadcasting. Certainly its direction has been substantially altered over the years through the influence of factors cited above. However, in my view this development, overall, has been beneficial for the broadcasting services, the listening public and educational interests alike. Today educational broadcasters reach a far larger portion of the public than they did in their earlier years. They provide mainly "soft core" educational programs rather than direct instruction. Nevertheless, the educational flavour of the broadcasts survive. Educational issues, achievements and expertise are injected constantly into the community consciousness through public radio programs. Educational events are promoted and celebrated through a medium reaching substantial audiences. The public profiles of academic institutions and their activities are lifted throughout Australia by educational public broadcasters in the act of providing enlightened broadcasting, rather than narrowcasting to tiny groups of selected students. 
Technological developments during the period of educational radio's evolution tend to support my contention that the most efficient use of radio broadcasting in serving the interests of education is as a promoter and a "friend maker". Teleconferencing and computer networking, for instance, are more viable, interactive and less expensive for most "one off" instructional applications than licensing and running a continuous radio service purely for instructional purposes. Governmental red tape and the high cost of technological access to wide audiences not necessarily interested in specific instruction at the moment it is being offered can be avoided by using more efficient closed network structures for pure educative purposes. Recently one of these has been developed as a technical "spin-off" of normal FM broadcasting.

In the past two years 6UVS-FM has successfully demonstrated the instructional capabilities of use of the FM Subcarrier. Essentially the process involves generating a second audio transmission "invisible" to listeners tuned to the main broadcast service. Through the use of inexpensive receiver/decoder units students are able to pick up the special transmissions. Being an exclusive system there is no limit to the amount of specificity or jargon a lecture or tutorial may contain since only those with decoders will have access to the narrowcast. Through the use of this technology 6UVS has been able to satisfy both the promotional and educative definitions of educational broadcasting by simultaneously providing one service doing each.

At the moment 6UVS is awaiting a decision on its request for another experimental licence to resume subcarrier broadcasts as well as permission to attempt to generate a second subcarrier. Regular licences for subcarrier applications will be available soon. No doubt most FM educational broadcasters will give this direction serious consideration as a means of reconciling teaching capacity with healthy audience size. The option is all the more attractive because the costs of subcarrier generation beyond those of providing a normal FM broadcast signal are negligible. Future refinements consistent with subcarrier capabilities include educational data transmission and slow scan television. This method of instructional reticulation could eventually equip every educational FM radio service with the potential of becoming a comprehensive audio visual and magnetic instructional medium. The main broadcast signal can be left unencumbered to pursue an accessible profile essential to the formation of positive community perceptions of education.

The attitudes of successive governments toward the plight of the educational public broadcasters have been, for the most part, unassisting at best. The formation of the Public Broadcasting Foundation (PBF) which kindled so much hope in public broadcasting circles is a tragic shadow of what was originally proposed. Laughably underfunded and over solicited, the PBF is generally unwilling to assist educational broadcasters with any 
endowment whatsoever because most of the stations are judged to be "too large" or "too wealthy" relative to the small, struggling community stations.

What little government interest there is in public broadcasting seems to be aimed at the community access area, presumably since this is seen as "where all the votes are". Established educational broadcasters are often discriminated against in pursuit of government grants from a number of sources due to their age and history of achievements. For instance, money for government public education radio programs will usually be given to new broadcasting initiatives in preference to existing ones. Stations with an established reputation for actively producing these sort of programs are exempted from support while others with no prior experience in these program areas can get substantial fiscal assistance in inaugurating them.

The basic assumption held by politicians and bureaucrats alike seems to be that since universities, colleges and institutes have been supporting these community radio services for years, they are expected to continue to do so indefinitely. Therefore government is under no obligation whatsoever to help with the financial burden. Major government information campaign messages, many of them aimed specifically at the demographic segments targeted best by public radio stations, are routinely given to commercial broadcasters for paid air play and to public broadcasters with the anticipation they will be broadcast free of charge. The harder educational public broadcasters work to provide programs with educational. social and cultural merit, the more they are taken for granted by government decision makers who seem to forget they are independently and tenuously funded. The most ironic aspect of this paradox is that public broadcasting stations are expected to stretch their meagre resources even further for the sake of a little government goodwill while commercial broadcasters, flush with corporate profits, are subsidised on a vast scale by millions of dollars worth of government advertising.

If the point of these information campaigns is to educate the public; isn't it only common sense to involve those who are the singular experts at public education? A decision to provide public broadcasters with their "fair share" of governmental promotion monies has a number of advantages for governments. First of all it doesn't cost anything at all since it is only a readjustment of a predetermined allocation enlarging the target groups to include public radio audiences as well. Campaigns would be more effective because many (conservatively 1.5 million) Australians overlooked in the past would now be reached. Government would be exempted from the justifiable charge that it has not lifted a finger to help public and educational broadcasting initiatives.

Successive governments have much to answer for in shirking their responsibilities to play a positive role in both the educational and 
educative broadcasting fields. Educational public broadcasting has survived, adapted and matured in spite of a consistent governmental track record of ignoring the achievements as well as the chronic needs of the sector. It would appear that every conceivable self-funding option has now been exploited. If the tradition of political broken promises is to continue through the 1980s the inevitable outcome will be the degrading of educational broadcasting services and, one by one, the operations will be forced to close down.

State and federal governments have the option of allowing this destruction to take its course or to play their rightful roles ensuring that informed, varied broadcasting is a permanent fixture of Australia. Policy makers now have a unique opportunity to play a crucial part in stimulating the development of educational technology. Subcarrier technology along with satellite systems and the potential of educational television all have challenging implications for the quality of Australia's educational environment. Financial encouragement for these innovations would do much to restore our faith in the commitment of politicians to the pursuit of educational objectives. The cost efficiency of public radio has been unique in carrying out diversified, comprehensive services of high intellectual content on a "shoe string budget". There is no doubt that the next phase, utilisation of new technologies for the more specific tasks of instruction, will be executed within the same modest financial scale.

If educational public broadcasting was to disappear tomorrow, who would take up these tasks? It would cost the $\mathrm{ABC}$ almost twenty times more to duplicate the present services of educational public radio if a recent comparative cost survey commissioned by the Public Broadcasting Foundation is anything to go on. Keeping in mind that most independent educational broadcasters receive little if any direct government funding, the total bill to the taxpayer could realistically escalate by 10,000 percent. There is no doubt about it, the existence of independent educational broadcasting operations is a real bargain for the Commonwealth. Will these advantages now be fully utilised by allowing us to tool up to meet the educational needs of our society in the 21 st century or will the opportunities resulting from ten years of blood, sweat and tears expended by public broadcasters be squandered on indecision?

Please cite as: McGinnis, W. K. (1986). Educational radio in its third decade: Redefining the concept of educational broadcasting in terms of new expectations and financial restraint. Australian Journal of Educational Technology, 2(2), 57-62.

http: / / www.ascilite.org.au / ajet / ajet2 / mcginnis.html 